\title{
Article
}

\section{BRCA1/2 Mutation Types Do Not Affect Prognosis in Ovarian Cancer Patients}

\author{
Michalis Liontos ${ }^{1, *}++^{(D)}$, Eleni Zografos ${ }^{1,+} \mathbb{D}^{\mathbb{D}}$, Panagiotis Zoumpourlis ${ }^{1}$, Angeliki Andrikopoulou ${ }^{1}$ (D),

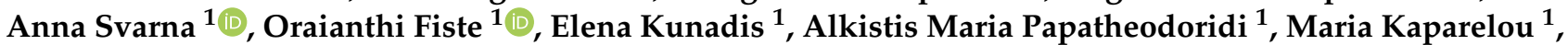 \\ Konstantinos Koutsoukos ${ }^{1}$, Nikoloas Thomakos ${ }^{2}$, Dimitrios Haidopoulos ${ }^{2}$, Alexandros Rodolakis ${ }^{2}$, \\ Meletios-Athanasios Dimopoulos ${ }^{1}$ (D) and Flora Zagouri ${ }^{1}$
}

1 Oncology Unit, Department of Clinical Therapeutics, Alexandra Hospital, National and Kapodistrian University of Athens, 11528 Athens, Greece; elzogra@med.uoa.gr (E.Z.); panos_zoubourlis@hotmail.com (P.Z.); aggandrikop@med.uoa.gr (A.A.); anna.svarna@hotmail.com (A.S.); ofiste@med.uoa.gr (O.F.); ekunadis@med.uoa.gr (E.K.); alkipapath@med.uoa.gr (A.M.P.); mkaparelou@yahoo.com (M.K.); koutsoukos.k@gmail.com (K.K.); mdimop@med.uoa.gr (M.-A.D.); florazagouri@yahoo.co.uk (F.Z.)

2 1st Department of Obstetrics and Gyencology, Alexandra Hospital, National and Kapodistrian University of Athens, 11528 Athens, Greece; thomakir@hotmail.com (N.T.); dhaidopoulos@hotmail.com (D.H.); arodolak@med.uoa.gr (A.R.)

* Correspondence: mlionto@med.uoa.gr; Tel.: +30-213-216-2845; Fax: +30-213-216-2511

+ These authors contributed equally to this work.

Citation: Liontos, M.; Zografos, E.; Zoumpourlis, P.; Andrikopoulou, A.; Svarna, A.; Fiste, O.; Kunadis, E.; Papatheodoridi, A.M.; Kaparelou, M.; Koutsoukos, K.; et al. BRCA1/2 Mutation Types Do Not Affect Prognosis in Ovarian Cancer Patients. Curr. Oncol. 2021, 28, 4446-4456. https: / / doi.org/10.3390/ curroncol28060377

Received: 6 October 2021

Accepted: 1 November 2021

Published: 3 November 2021

Publisher's Note: MDPI stays neutral with regard to jurisdictional claims in published maps and institutional affiliations.

Copyright: (c) 2021 by the authors. Licensee MDPI, Basel, Switzerland. This article is an open access article distributed under the terms and conditions of the Creative Commons Attribution (CC BY) license (https:/ / creativecommons.org/licenses/by/ $4.0 /)$.
Abstract: Background: High grade serous ovarian carcinoma (HGSOC) is the most lethal type of epithelial ovarian cancer, with a prevalence of germline $B R C A 1 / 2$ mutations as high as $20 \%$. Our objective is to determine whether the location of mutations in the different domains of the BRCA1/2 genes affects the clinical outcome of HGSOC patients. Methods: A total of 51 women with BRCA1 or $B R C A 2$ mutated ovarian cancer were identified. Progression-free survival (PFS) and overall survival (OS) were analyzed. Results: In our study cohort, 35 patients were carriers of germline mutations in BRCA1 and 16 in BRCA2. The median PFS time following completion of the primary therapy was 23.8 months (95\% CI 20.1-27.5) and the median OS was 92.9 months (95\% CI 69.8-116.1) in all $B R C A$ carriers. After multivariate analysis, no significant association among the location or type of $B R C A 1 / 2$ mutation with PFS or OS was identified. Notably, significant differences in PFS between carriers of identical mutations in the same BRCA gene were detected. Conclusions: Among HGSOC patients, $B R C A 1 / 2$ carriers with mutations in different locations of the genes show no significant difference in survival outcomes, in terms of PFS and OS, suggesting the potential effect of other genetic abnormalities and co-contributing risk factors.

Keywords: ovarian cancer; BRCA; germline mutations; survival

\section{Introduction}

Despite advances in therapy, ovarian cancer remains a major health concern worldwide, with an estimated 313,959 new cases predicted for 2020 [1]. Many of these cases have been attributed to germline mutations in BRCA1 and BRCA2 genes, which is a frequent molecular event in women with the most lethal and prevalent type of epithelial ovarian cancer, high grade serous ovarian carcinoma (HGSOC) [2]. More specifically, the prevalence of germline $B R C A 1 / 2$ mutations in patients with this histology is up to $20 \%$, while an additional 5-10\% bear tumors with somatic mutations [3]. This information has important clinical implications since individuals with deleterious $B R C A$ mutations compared to non-carriers are known to have superior prognosis [2], exhibit better responses to platinum-based chemotherapy [4], and derive greater benefit from PARP inhibition treatment either in the frontline [3,5,6], or in the platinum-sensitive relapse setting [7-9]. 
The genetic basis for ovarian cancer predisposition was originally established with the identification of BRCA1 (OMIM\# 113705) and BRCA2 (OMIM\# 600185), which are both tumor suppressor genes implicated in the mechanism of Homologous Recombination (HR) repair of DNA double-strand breaks [10]. However, despite the phenotypic similarities induced by $B R C A 1$ or $B R C A 2$ gene disruption, the proteins encoded by these genes are involved in different macromolecular complexes and have distinct biological roles in the regulation of the HR mechanism [11]. On the one hand, each functional domain of BRCA1 interacts with tumor suppressors, DNA repair proteins and cell cycle regulators to activate DNA damage checkpoints and repair, including but not limited to HR [12]. On the other hand, BRCA2 is not a versatile protein since its activity mainly involves regulation of RAD51, which is required for HR repair [13]. The different roles of $B R C A 1$ and $B R C A 2$ in genome protection confer distinct breast and ovarian cancer predisposition in mutation carriers [11]. Specifically, results of previous studies suggest that patients with high grade serous ovarian cancer and either BRCA1 or BRCA2 mutations have different clinicopathological features, response to treatment, and prognosis [14,15]. However, the etiology of why some $B R C A$ carriers fare better than others is unclear.

To date, little is known about the clinical impact of differently mutated $B R C A 1 / B R C A 2$ domains on high grade serous ovarian cancer prognosis. In fact, both $B R C A$ genes have complex genomic structures and encode relatively large proteins that are organized into distinct structural domains, each of which has selected binding partners and thus differential functions [16]. The BRCA1 gene consists of 24 exons and the BRCA2 of 27 exons, coding for protein products of 1863 and 3418 amino acids, respectively. BRCA1 is composed of the zinc-binding N-terminal RING finger domain that is recognized as a ubiquitin E3 ligase enzyme, and the phosphoprotein-binding C-terminal BRCT domain, which is a transcriptional activation region that contributes to DNA repair [17]. Notably, exons 11-13 encode modular protein domains that act as binding sites for various macromolecules, such as RB, PALB2, c-Myc, RAD50,51 [17]. Concerning BRCA2, it encompasses a large DNA-binding domain (DBD) and eight copies of a 20-30 amino acid motif, known as BRC repeats, that bind RAD51 to regulate HR repair of DNA [18]. More than 2200 BRCA1 and 2600 BRCA2 pathogenic germline variants have been reported in the ClinVar database, maintained at the National Institutes of Health (NIH). The mutations reported so far are scattered throughout the genomic sequence of both genes and affect their structural and functional integrity in a different manner.

There has been limited previous evidence on the effects of cancer-causing $B R C A 1 / 2$ gene mutations located in different domains of the molecules on the prognosis of HGSOC patients. Thus, the current report aimed to evaluate the correlation between location of mutation within the $B R C A$ genes and clinical outcome, in the context of progression-free survival (PFS) and overall survival (OS), in high grade serous ovarian cancer patients.

\section{Results}

\subsection{Characteristics of the Study Cohort}

Fifty-one patients with high grade serous ovarian carcinoma that bared germline mutations in the BRCA1/2 genes were included in this study. The clinical, genetic and treatment characteristics of these patients are summarized in Table 1. More specifically, the median age of the patients was 54.2 years. Most patients presented at advanced stages (III/IV: $84.4 \%$ ). Concerning the surgical management, $60.8 \%$ of the patients underwent primary debulking surgery and the remaining had interval cytoreductive surgery. The outcome of the surgical intervention was complete debulking (no residual disease) in 45 patients (88.2\%). Notably, 39.2\% of ovarian cancer patients received bevacizumab and in $66.7 \%$ of cases a PARP inhibitor was administered. 
Table 1. Clinical, genetic, and treatment characteristics of BRCA1/2-mutated serous ovarian cancer patients.

\begin{tabular}{|c|c|c|}
\hline Characteristic & & \\
\hline & Median (25th-75th Perc) & Missing (\%) \\
\hline \multirow[t]{2}{*}{ Age } & $54.2(45.8-62.1)$ & $0(0)$ \\
\hline & $n$ & $(\%)$ \\
\hline \multicolumn{3}{|l|}{ Stage } \\
\hline II & 8 & $15.7 \%$ \\
\hline IIIA/IIIB & 4 & $7.9 \%$ \\
\hline IIIC & 29 & $56.9 \%$ \\
\hline IV & 10 & $19.6 \%$ \\
\hline \multicolumn{3}{|l|}{ Debulking Surgery } \\
\hline Primary & 31 & $60.8 \%$ \\
\hline Interval & 20 & $39.2 \%$ \\
\hline \multicolumn{3}{|l|}{ Surgical Outcome } \\
\hline Complete & 45 & $88.2 \%$ \\
\hline Optimal/Suboptimal & 6 & $11.8 \%$ \\
\hline \multicolumn{3}{|l|}{ Mutated Gene } \\
\hline BRCA1 & 35 & $68.6 \%$ \\
\hline BRCA2 & 16 & $31.4 \%$ \\
\hline \multicolumn{3}{|l|}{ Type of mutation } \\
\hline Deletion & 26 & $51.0 \%$ \\
\hline Frameshift & 4 & $7.8 \%$ \\
\hline Insertion & 4 & $7.8 \%$ \\
\hline Missense & 17 & $33.3 \%$ \\
\hline \multicolumn{3}{|l|}{ Affected region } \\
\hline RING domain & 3 & $5.9 \%$ \\
\hline BRCA1 exons 11-13 & 16 & $31.4 \%$ \\
\hline BRCT domain & 16 & $31.4 \%$ \\
\hline RAD51 binding domain & 11 & $21.6 \%$ \\
\hline DNA binding domain & 5 & $9.8 \%$ \\
\hline \multicolumn{3}{|l|}{$\begin{array}{l}\text { Bevacizumab } \\
\text { administration }\end{array}$} \\
\hline No & 31 & $60.8 \%$ \\
\hline Yes & 20 & $39.2 \%$ \\
\hline \multicolumn{3}{|l|}{$\begin{array}{l}\text { PARP inhibitor } \\
\text { administration }\end{array}$} \\
\hline No & 17 & $33.3 \%$ \\
\hline Yes & 34 & $66.7 \%$ \\
\hline
\end{tabular}

\subsection{Location of Mutations in BRCA and Survival in the Study Cohort}

Among the 51 participants of the study cohort, 35 were found to carry a BRCA1 mutation and 16 patients a BRCA2 mutation. Over half of the detected mutations were deletions $(51.0 \%)$, while $33.3 \%$ of our group of patients harbored missense mutations. Concerning the BRCA1-mutated ovarian cancers, an equal percentage of mutations were located either within exons $11-13(45.7 \%)$ or in the BRCT domain (45.7\%). Among the 16 BRCA2 carriers of the study cohort, 11 (68.8\%) had mutations located within the RAD51binding domain of the gene.

Median follow-up of the BRCA1/2 mutation carriers was 45.8 months. In our cohort, the median time to the first recurrence (PFS) of disease following completion of the primary therapy was 23.8 months (95\% CI 20.1-27.5) (Figure 1). The median OS from the date of diagnosis was 92.9 months (95\% CI 69.8-116.1) in all BRCA carriers, as is shown using Kaplan-Meier survival estimates (Figure 2). 


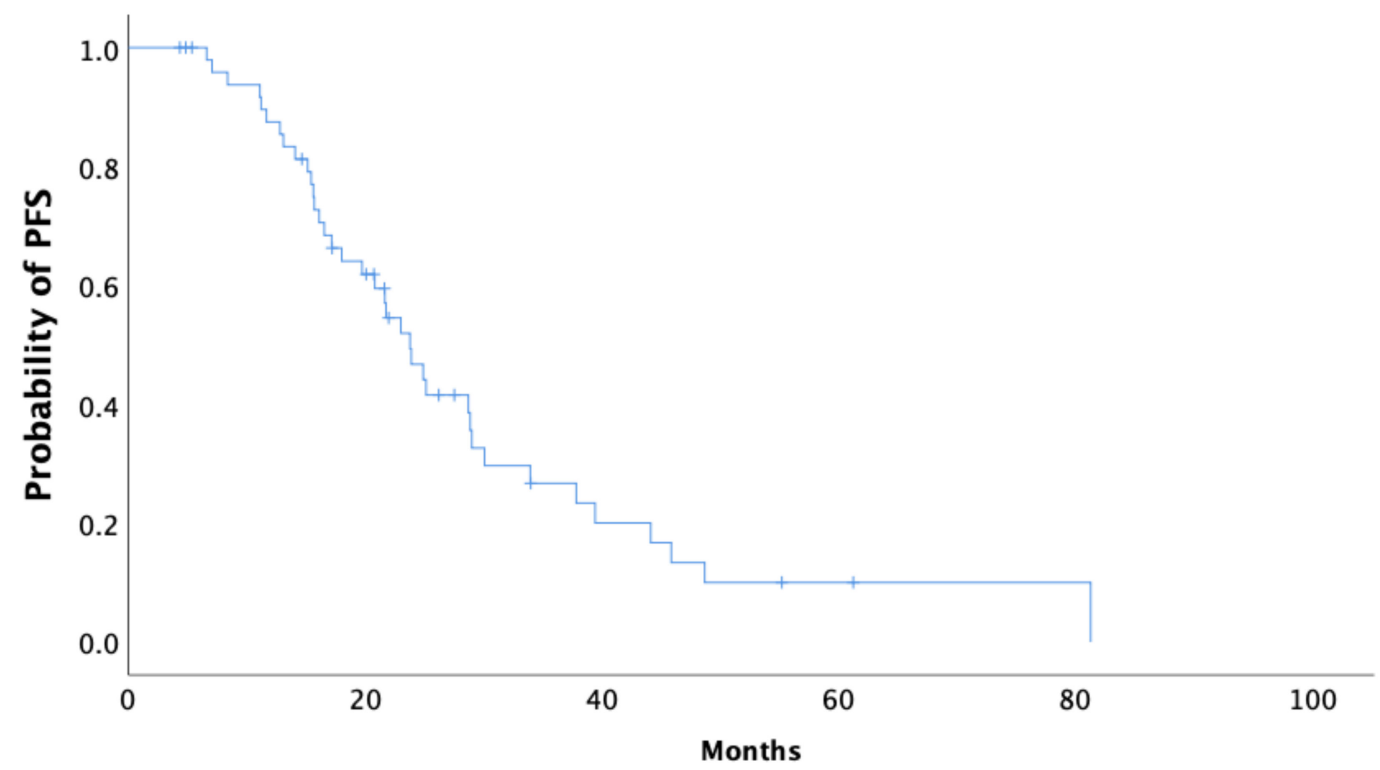

Figure 1. Kaplan-Meier curve of progression-free survival (PFS) of all BRCA1/2 carriers.

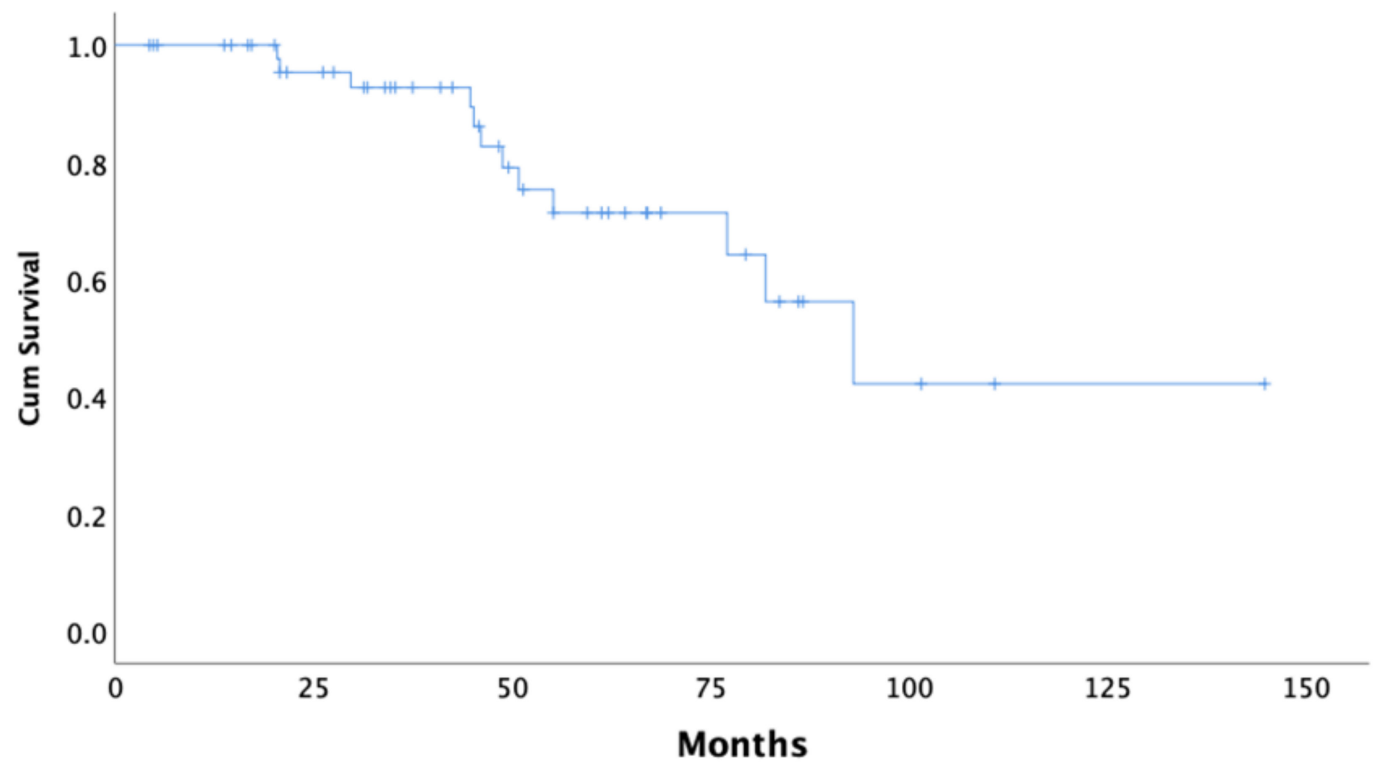

Figure 2. Kaplan-Meier curve of overall survival (OS) of all $B R C A 1 / 2$ carriers.

The univariate analysis showed that there was no significant association of the location or type of BRCA1/2 mutation with PFS or OS duration (Table 2). Despite numerical differences, pairwise comparisons between different functional domains of each gene also did not indicate any significant difference in either PFS or OS (Figure S1). The only characteristic that showed a correlation with survival outcome was surgical outcome, with patients having no residual disease following debulking surgery exhibiting a significantly higher PFS $(p<0.001)$ and OS $(p=0.028)$ compared to those with optimal or suboptimal surgical results (Table 2 ). 
Table 2. Median PFS, OS with 95\% CI, Univariate analysis.

\begin{tabular}{|c|c|c|c|c|c|c|}
\hline & \multicolumn{3}{|c|}{ PFS } & \multicolumn{3}{|c|}{ OS } \\
\hline & Median & $95 \% \mathrm{CI}$ & $p$-Value * & Median & $95 \% \mathrm{CI}$ & $p$-Value \\
\hline Age & & & 0.867 & & & 0.467 \\
\hline$\leq 65$ & 23.9 & $18.4-29.3$ & & 92.9 & $59.8-126.1$ & \\
\hline$>65$ & 23.0 & $20.3-25.7$ & & NR & NR & \\
\hline Stage & & & 0.155 & & & 0.173 \\
\hline II/IIIA/IIIB & 45.8 & NR & & NR & NR & \\
\hline IIIC/IV & 21.7 & $13.9-29.5$ & & 81.9 & $63.6-100.2$ & \\
\hline Mutant gene & & & 0.828 & & & 0.405 \\
\hline BRCA1 & 23.0 & $19.1-26.9$ & & 81.9 & - & \\
\hline$B R C A 2$ & 23.8 & $16.3-31.3$ & & 92.9 & 32.9-153.7 & \\
\hline Surgical outcome & & & $<0.001$ & & & 0.028 \\
\hline Complete & 24.9 & $18.4-31.4$ & & 92.9 & $69.3-116.7$ & \\
\hline Optimal/Suboptim & 11.1 & $2.5-19.8$ & & 45.2 & $17.4-72.8$ & \\
\hline Surgical outcome & & & 0.459 & & & 0.178 \\
\hline Primary & 23.0 & $12.1-33.9$ & & NR & NR & \\
\hline Interval & 23.9 & $19.9-27.8$ & & 81.9 & $36.7-127.1$ & \\
\hline Type of mutation & & & & & & 0.187 \\
\hline Deletion & 19.7 & $13.4-26.1$ & & 92.9 & $40.8-145.2$ & \\
\hline Frameshift & 30.1 & $21.1-39.1$ & & NR & NR & \\
\hline Missense & 23.0 & $18.1-27.9$ & & NR & NR & \\
\hline Affected domain & & & 0.339 & & & 0.882 \\
\hline RING domain & 15.6 & - & & 77.1 & 10.9-NR & \\
\hline $\begin{array}{c}\text { BRCA1 exons } \\
11-13\end{array}$ & 21.8 & $18.1-25.5$ & & 81.9 & - & \\
\hline BRCT domain & 28.7 & $19.9-37.6$ & & NR & NR & \\
\hline $\begin{array}{l}\text { DNA Binding } \\
\text { domain }\end{array}$ & 19.7 & $12.9-26.6$ & & NR & NR & \\
\hline $\begin{array}{c}\text { RAD51 binding } \\
\text { domain }\end{array}$ & 33.9 & $16.0-51.9$ & & 92.9 & $25.9-160.1$ & \\
\hline Bevacizumab & & & 0.707 & & & 0.214 \\
\hline No & 23.9 & $19.6-28.2$ & & NR & NR & \\
\hline Yes & 21.8 & $6.6-36.9$ & & 81.9 & $69.8-116.1$ & \\
\hline
\end{tabular}

* Log-rank test; NR = not reached.

We further explored the effect of individual mutations that were common among patients in our cohort. Ten individual mutations were common among two or more patients. The results of the analysis of PFS among patients harboring the same mutation are graphically presented in Figure 3, showing noteworthy differences between carriers of identical mutations in the same $B R C A$ gene. 


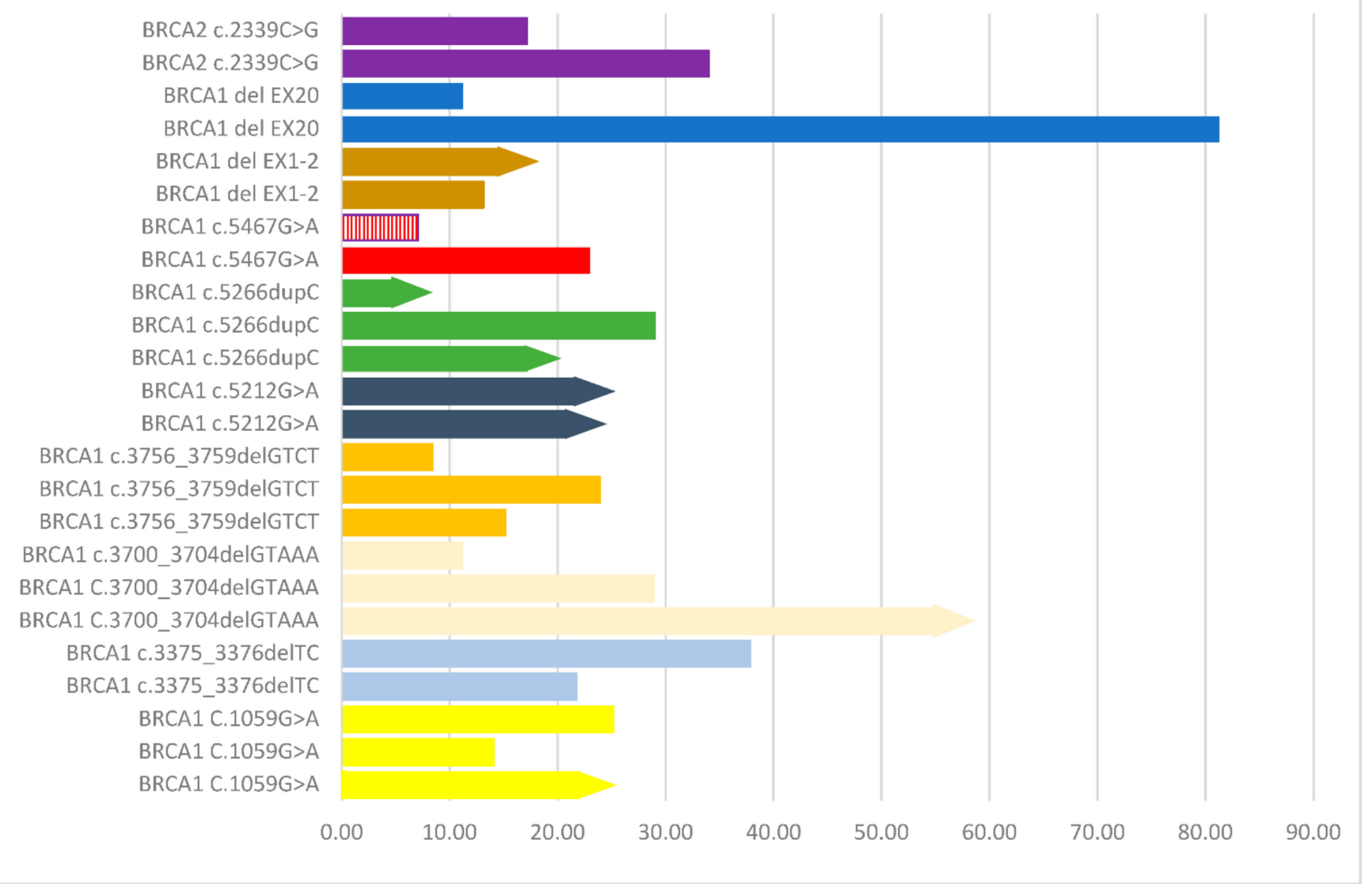

Figure 3. Analysis of progression free survival (PFS) among patients harboring the same mutation in the same BRCA gene. Identical mutations are depicted with the same color. Bars with an arrow at the end of them indicate no disease progression. The bar in red and white stripes indicates a case that received a PARP inhibitor as first-line therapy.

\section{Discussion}

The $B R C A 1$ and $B R C A 2$ gene status undisputedly plays a key role in genome integrity and hereditary ovarian cancer pathogenesis; however, the frequency and precise prognostic role of $B R C A$ mutations at different locations of the genes remains largely unknown. In this study, we addressed in a series of 51 high grade serous ovarian cancer (HGSOC) patients the correlation between $B R C A 1 / 2$ genotype and their survival, in accordance with the functional regions of the proteins. Our results demonstrated that $B R C A 1$ mutations were mainly located either in exons 11-13 (16/35), which encode modular protein binding domains, or in the BRCT domain (16/35). Additionally, among ovarian cancer patients harboring BRCA2 mutations, most of them were located at exon $11(11 / 16)$, affecting the RAD51-binding domain of the protein. Despite these noteworthy observations, data from our cohort of patients showed that mutations occurring at different locations of the BRCA1 and BRCA2 genes did not impact the survival outcome, in terms of PFS and OS. Additionally, those treated with PARP inhibitors, which carried distinct germline mutations located at different domains of the BRCA1/2 genes, exhibit no difference in survival among each other. These are important findings in the understanding of the genomic background of BRCA-mutated HGSOC and their implications are discussed in detail in the following section.

Several lines of evidence indicate that specific $B R C A 1 / 2$ mutations could have prognostic and predictive significance among ovarian cancer patients. First of all, it has been suggested that the site of $B R C A$ mutation is associated with relative susceptibility to ovarian cancer, underlying a genotype-phenotype correlation. Characteristically, mutations 
located within the $3^{\prime}$ portion of $B R C A 1$ have long shown to be less likely to lead to OC compared to the ones found in the $5^{\prime}$ end of the gene [19-21]. Analogously, truncating BRCA2 mutations that lie within the Ovarian Cancer Cluster Region (OCCR) of exon 11 (nucleotides 3035-6629) have been correlated with significantly higher risk of OC [22-24]. These mutations lie within the RAD51-binding domain (RAD51-BD) of the BRCA2 gene; ovarian cancer patients harboring mutations located at the RAD51-BD (exon 11) of the $B R C A 2$ gene have prolonged survival compared to mutations occurring at other locations of the $B R C A 2$ gene or to noncarriers [25]. Despite not detecting any strong correlations between $B R C A 1$ mutation location and survival outcome, we found that $45.7 \%(16 / 35)$ of $B R C A 1$ mutations were located towards the $5^{\prime}$ end of the gene and are known to target the highly conserved C-terminal BRCT repeats that function as a phosphoprotein-binding domain. In addition, differences in survival outcomes according to the BRCA2 mutation position were not observed in our study. When comparing our results to those of older studies, it must be pointed out that there are also multiple reports that showed no significant differences on OC risk associated with specific BRCA2 regions [26,27], in accordance with our findings. The conflicting findings reported in the literature as well as the different survival outcomes of carriers of the same mutations found in this study might indicate the presence of additional factors that modify the risk. Genetic factors such as TP53 mutations [28] and clinical factors including disease extent that determines initial therapeutic approach [29] are known to affect survival irrespective of the presence of $B R C A 1 / 2$ mutations. Whether BRCA1/2 mutation types may affect disease extent at diagnosis, however, remains currently elusive.

Interestingly, we observed noteworthy differences, in terms of PFS duration, between carriers of identical mutations in the same $B R C A$ gene, as is shown with bars of the same color in the graph of Figure 3. These dissimilarities in outcome further substantiate the notion that the clinical course of ovarian cancer is not solely determined by mutation type/location. Especially in the case of HGSOC, recent evidence suggests that there are several other genetic abnormalities and co-contributing factors that determine the biology and extent of the disease [30]. Specifically, about half of HGSOC cases are characterized by homologous recombination repair deficiency (HRD) due to chromosomal instability, which is caused by a multitude of additional genetic abnormalities, apart from BRCA1/2 mutations [31]. From this perspective, HRD score has been used to acquire information regarding the magnitude of the potential treatment benefit of niraparib, a PARP inhibitor [9].

The presence of a deleterious BRCA mutation has been shown to affect survival not only in primary ovarian carcinoma but even in the fairly common recurrent setting, with $75 \%$ of HGSOC patients relapsing within two years of diagnosis [32,33]. Advances in current interventions, including cytoreductive surgery, and the incorporation of targeted therapy in the chemotherapeutic armamentarium, seem to collectively impact progressionfree survival [34,35]. Characteristically, PARP (poly (ADP-ribose) polymerase) inhibitors lead to the accumulation of DNA single strand breaks (SSBs), inducing the formation of double strand breaks (DSBs); thus, they are known for their effectiveness against tumors characterized by faulty homologous repair mechanisms (HRD), such as BRCA-mutated tumors [36]. In the context of this work, we noted that OC patients treated with PARP inhibitors exhibit similar survival outcomes, independently to the BRCA1/2 mutation location. Yet, according to the literature, tumors carrying pathogenic mutations that affect the RING domain of BRCA1 have been shown to respond poorly to PARP inhibition and rapidly develop resistance, due to the reduction of BRCA1/BARD1 heterodimerization and the inhibition of its ubiquitin ligase function [37]. Therefore, determining how a specific mutation affects the structure of BRCA1/2 has potential implications for the evaluation of existing treatment options. However, in our cohort, we detected only three patients with BRCA1 mutations affecting this specific region of the gene, possibly implying that sample size may have contributed to a lack of statistical significance when stratifying the survival analyses by mutation position. 
Certain limitations of this study should be acknowledged, such as small sample size that might undervalue the exact impact of the mutation site on survival outcome, rendering our results merely indicative and in need of further confirmation in a larger cohort of patients. Furthermore, it is important to point out that in our study cohort were only included women with germline BRCA1/2 mutations due to limited availability of tissue testing during the period of diagnosis. It is known that in certain cases presence of germline $B R C A 1 / 2$ mutations may not be related to tissue carcinogenesis either due to persistence of the wild-type allele (no Loss of Heterozygosity) [38] or due to reversing mutations in the tumor [39]. Therefore, accumulating data from ovarian cancer patients who undergo full gene sequencing in both tissue and blood will eventually strengthen our understanding of the precise effect of specific rearrangements and mutations on survival outcome.

\section{Materials and Methods}

\subsection{Patients}

We retrospectively searched our institutional database for patients with advanced stage (II-IV) high-grade serous carcinoma that tested positive for germline mutations of $B R C A 1$ and BRCA2 genes, during a 5-year period (2015-2019). Informed consent was obtained from all patients involved in the study, with respect to their treatment regimen, genetic testing procedure, as well as granting access to their medical records for the purposes of data acquisition. The clinicopathological characteristics that were acquired from medical reports included age at diagnosis, stage, surgical management, BRCA1/2 mutation status, targeted therapy, progression of the disease, and overall survival. The present study received approval from the Institutional Review Board (IRB) of Alexandra Hospital in Athens, Greece and was carried out in conformity with the ethical guidelines of the Declaration of Helsinki.

\subsection{Genetic Analysis}

Blood samples were collected from each participant for germline DNA testing when the patients were referred to a Genetic Counseling Unit. All participants were screened for BRCA1 and BRCA2 mutations, either by Sanger sequencing using Applied Biosystems' 3130XL Genetic Analyzer (Thermo Fisher Scientific, Carlsbad, CA, USA) or by massive parallel sequencing using the TruSight Cancer panel (Illumina, San Diego, CA, USA) on a MiSeq Analyzer, as previously described [40]. Carriers of variants of uncertain/unknown significance (VUSs) were deemed as non-carriers. The NM_007294/ENST00000357654 and NM_000059/ENST00000380152 were used as the reference sequences for BRCA1 and $B R C A 2$ genes, respectively. According to the typical BRCA exon numbering used, the $B R C A 1$ gene has 24 exons and encodes 1863 amino acids, while BRCA2 consists of 27 exons and encodes 3418 amino acids (Figure 4).

\subsection{Statistical Analysis}

Continuous variables were summarized by using descriptive statistical measures (median and percentiles (25th, 75th)). Additionally, categorical variables were displayed as percentages with the use of frequency tables (N, \%). Overall Survival (OS) was defined as the time interval from initiation of chemotherapy until death from any cause. Progressionfree Survival (PFS) was defined as the time between the start of chemotherapy and the date of progression. Alive patients were censored at the date they were last conducted. In order to describe and visualize the effect of categorical variables on OS and PFS, KaplanMeier estimates were utilized. Notably, log-rank tests were used to assess the prognostic value of categorical variables on clinical outcomes. These factors were correlated with PFS and OS according to hazard ratios and their 95\% confidence intervals estimated from univariate Cox proportional hazards models. All statistical analyses were performed using the SPSS software. 

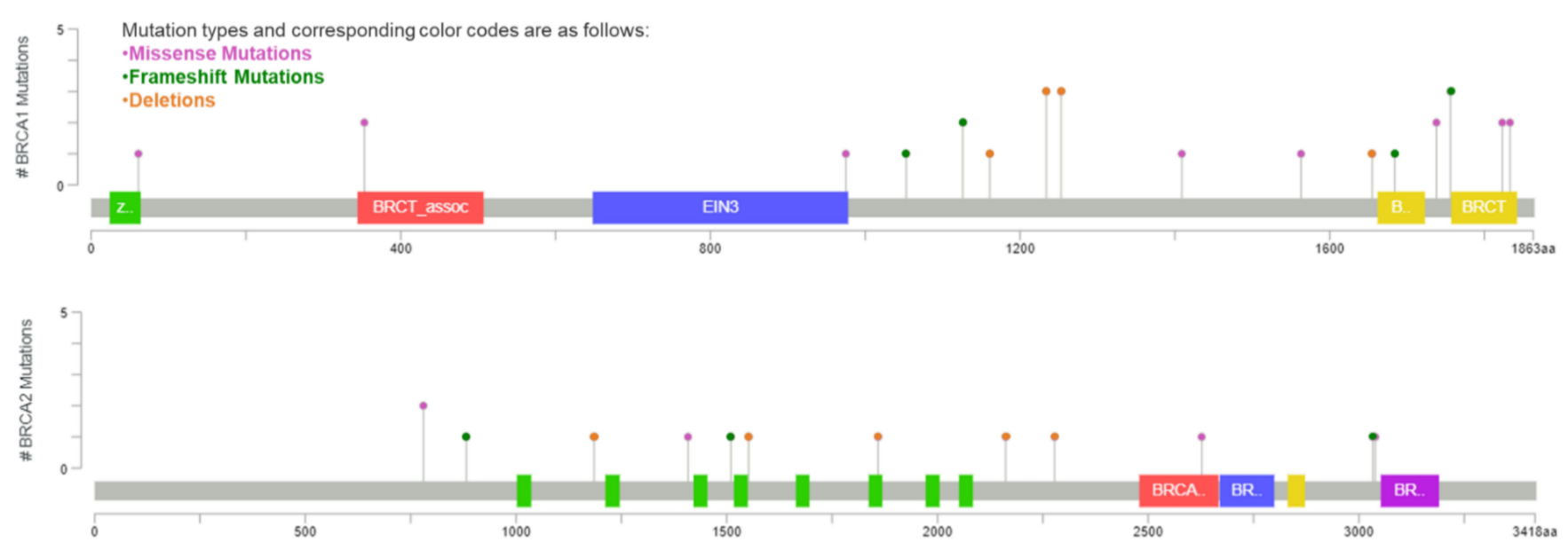

Figure 4. Germline mutations of BRCA1 and BRCA2 genes in the study cohort of ovarian cancer patients (whole exon deletions are not depicted). Mutation diagram circles are colored with respect to the corresponding mutation types. Abbreviations: zf-C3HC4: zinc finger, C3HC4 type (RING finger) (aa 24-64), BRCT_assoc: serine-rich domain associated with BRCT (aa 344-507), EIN3: ethylene insensitive 3 (aa 648-978), BRCT: BRCA1 C Terminus (BRCT) domain (aa 1757-1842), BRCA-2_helical: BRCA2, helical (aa 2479-2667), BRCA-2_OB1: BRCA2, oligonucleotide/oligosaccharide-binding, domain 1 (aa 2670-2799), BRCA-2_OB3: BRCA2, oligonucleotide/oligosaccharide-binding, domain 3 (aa 3052-3190).

\section{Conclusions}

In conclusion, this study offers an initial assessment of genotype-phenotype interplay in BRCA-mutated ovarian cancer, based on mutation location analysis and its effect on survival outcome. Future studies examining the type of mutation in combination with mutation site within the gene could offer further insight into the multifaceted issue of ovarian cancer prognosis. In addition, further investigations exploring the genotypephenotype correlations of specific $B R C A 1$ and $B R C A 2$ mutations that differentiate prognosis among family members who are carriers of the same mutations are needed to clarify the role of other genetic abnormalities and co-contributing risk factors in the clinical course of $B R C A$-mutated ovarian cancer patients.

Supplementary Materials: The following are available online at https:/ / www.mdpi.com/article / 10.3390 / curroncol28060377/s1, Figure S1: Pairwise comparisons of PFS and OS between different functional domains of BRCA1 (A,B) and BRCA2 (C,D) gene.

Author Contributions: M.L.; Conceptualization, methodology, formal analysis, writing-review and editing, E.Z.; data curation, investigation, writing—original draft preparation, P.Z., A.A., A.S., O.F., E.K., A.M.P. and M.K.; data Acquisition, curation, investigation, K.K., N.T. and D.H.; supervision, draft editing-review; A.R., M.-A.D. and F.Z.: conceptualization, project administration, supervision, draft editing. All authors have read and agreed to the published version of the manuscript.

Funding: This research received no external funding.

Institutional Review Board Statement: The study was conducted according to the guidelines of the Declaration of Helsinki and approved by the Institutional Review Board of Alexandra Hospital in Athens (Ethics code: 8379/17-06-2020), Greece.

Informed Consent Statement: Informed consent was obtained from all subjects involved in the study.

Data Availability Statement: No new data were created or analyzed in this study. Data sharing is not applicable to this article.

Conflicts of Interest: The authors declare the following financial interests/personal relationships which may be considered as potential competing interests: Liontos, receiving honoraria by Roche, Astra Zeneca, Astellas, MSD, Janssen, BMS and IPSEN, Koutsoukos, receiving honoraria by Roche, BMS, MSD and IPSEN, Zagouri receiving honoraria by Roche, Novartis, Eli-Lilly and Pfizer, Dimopoulos, receiving honoraria by Janssen, Celgene, Takeda, Amgen, Genesis Pharma and BMS. Zo- 
grafos, Zoumpourlis, Andrikopoulou, Svarna, Fiste, Kunadis, Papatheodoridi, Kaparelou, Thomakos, Haidopoulos and Rodolakis declare no conflict of interest.

\section{References}

1. Sung, H.; Ferlay, J.; Siegel, R.L.; Laversanne, M.; Soerjomataram, I.; Jemal, A.; Bray, F. Global Cancer Statistics 2020: GLOBOCAN Estimates of Incidence and Mortality Worldwide for 36 Cancers in 185 Countries. CA Cancer J. Clin. 2021, 71, 209-249. [CrossRef]

2. Bell, D.; Berchuck, A.; Birrer, M.; Chien, J.; Cramer, D.W.; Dao, F.; Dhir, R.; Disaia, P.; Gabra, H.; Glenn, P.; et al. Integrated genomic analyses of ovarian carcinoma. Nature 2011, 474, 609-615. [CrossRef]

3. Ray-Coquard, I.; Pautier, P.; Pignata, S.; Pérol, D.; González-Martín, A.; Berger, R.; Fujiwara, K.; Vergote, I.; Colombo, N.; Mäenpää, J.; et al. Olaparib plus Bevacizumab as First-Line Maintenance in Ovarian Cancer. N. Engl. J. Med. 2019, 381, 2416-2428. [CrossRef]

4. Cohen, P.A.; Powell, A.; Böhm, S.; Gilks, C.B.; Stewart, C.J.; Meniawy, T.; Bulsara, M.; Avril, S.; Brockbank, E.C.; Bosse, T.; et al. Pathological chemotherapy response score is prognostic in tubo-ovarian high-grade serous carcinoma: A systematic review and meta-analysis of individual patient data. Gynecol. Oncol. 2019, 154, 441-448. [CrossRef]

5. González-Martín, A.; Pothuri, B.; Vergote, I.; Christensen, R.D.; Graybill, W.; Mirza, M.R.; McCormick, C.; Lorusso, D.; Hoskins, P.; Freyer, G.; et al. Niraparib in Patients with Newly Diagnosed Advanced Ovarian Cancer. N. Engl. J. Med. 2019, 381, $2391-2402$. [CrossRef] [PubMed]

6. Moore, K.; Colombo, N.; Scambia, G.; Kim, B.-G.; Oaknin, A.; Friedlander, M.; Lisyanskaya, A.; Floquet, A.; Leary, A.; Sonke, G.; et al. Maintenance Olaparib in Patients with Newly Diagnosed Advanced Ovarian Cancer. N. Engl. J. Med. 2018, 379, $2495-2505$. [CrossRef]

7. Coleman, R.L.; Oza, A.M.; Lorusso, D.; Aghajanian, C.; Oaknin, A.; Dean, A.; Colombo, N.; Weberpals, J.I.; Clamp, A.; Scambia, G.; et al. Rucaparib maintenance treatment for recurrent ovarian carcinoma after response to platinum therapy (ARIEL3): A randomised, double-blind, placebo-controlled, phase 3 trial. Lancet 2017, 390, 1949-1961. [CrossRef]

8. Ledermann, J.; Harter, P.; Gourley, C.; Friedlander, M.; Vergote, I.; Rustin, G.; Scott, C.L.; Meier, W.; Shapira-Frommer, R.; Safra, T.; et al. Olaparib maintenance therapy in patients with platinum-sensitive relapsed serous ovarian cancer: A preplanned retrospective analysis of outcomes by BRCA status in a randomised phase 2 trial. Lancet Oncol. 2014, 15, 852-861. [CrossRef]

9. Mirza, M.R.; Monk, B.J.; Herrstedt, J.; Oza, A.M.; Mahner, S.; Redondo, A.; Fabbro, M.; Ledermann, J.A.; Lorusso, D.; Vergote, I.; et al. Niraparib Maintenance Therapy in Platinum-Sensitive, Recurrent Ovarian Cancer. N. Engl. J. Med. 2016, 375, $2154-2164$. [CrossRef] [PubMed]

10. Powell, S.N.; Kachnic, L.A. Roles of BRCA1 and BRCA2 in homologous recombination, DNA replication fidelity and the cellular response to ionizing radiation. Oncogene 2003, 22, 5784-5791. [CrossRef] [PubMed]

11. Venkitaraman, A.R. Cancer Susceptibility and the Functions of BRCA1 and BRCA2. Cell 2002, 108, 171-182. [CrossRef]

12. Roy, R.; Chun, J.; Powell, S.N. BRCA1 and BRCA2: Different roles in a common pathway of genome protection. Nat. Rev. Cancer 2012, 12, 68-78. [CrossRef]

13. Moynahan, M.E.; Pierce, A.J.; Jasin, M. BRCA2 Is Required for Homology-Directed Repair of Chromosomal Breaks. Mol. Cell 2001, 7, 263-272. [CrossRef]

14. Yang, D.; Khan, S.; Sun, Y.; Hess, K.; Shmulevich, I.; Sood, A.K.; Zhang, W. Association of BRCA1 and BRCA2 Mutations with Survival, Chemotherapy Sensitivity, and Gene Mutator Phenotype in Patients With Ovarian Cancer. JAMA 2011, 306, 1557-1565. [CrossRef]

15. Liu, J.; Cristea, M.C.; Frankel, P.; Neuhausen, S.L.; Steele, L.; Engelstaedter, V.; Matulonis, U.; Sand, S.; Tung, N.; Garber, J.E.; et al. Clinical characteristics and outcomes of BRCA-associated ovarian cancer: Genotype and survival. Cancer Genet. 2012, 205 , 34-41. [CrossRef]

16. Van Der Groep, P.; Van Der Wall, E.; Van Diest, P.J. Pathology of hereditary breast cancer. Cell. Oncol. 2011, 34, 71-88. [CrossRef]

17. Clark, S.L.; Rodriguez, A.M.; Snyder, R.R.; Hankins, G.D.; Boehning, D. Structure-Function of the Tumor Suppressor Brca1. Comput. Struct. Biotechnol. J. 2012, 1, e201204005. [CrossRef]

18. Welcsh, P.L.; King, M.C. BRCA1 and BRCA2 and the genetics of breast and ovarian cancer. Hum. Mol. Genet. 2001, 10, 705-713. [CrossRef] [PubMed]

19. Gayther, S.A.; Warren, W.; Mazoyer, S.; Russell, P.A.; Harrington, P.A.; Chiano, M.; Seal, S.; Hamoudi, R.; Van Rensburg, E.J.; Dunning, A.M.; et al. Germline mutations of the BRCA1 gene in breast and ovarian cancer families provide evidence for a genotype-Phenotype correlation. Nat. Genet. 1995, 11, 428-433. [CrossRef] [PubMed]

20. Holt, J.T.; Thompson, M.E.; Szabo, C.; Robinson-Benion, C.; Arteaga, C.L.; King, M.-C.; Jensen, R.A. Growth retardation and tumour inhibition by BRCA1. Nat. Genet. 1996, 12, 298-302. [CrossRef] [PubMed]

21. Thompson, D.; Easton, D. Variation in BRCA1 cancer risks by mutation position. Cancer Epidemiol. Biomarks Prev. 2002, 11, 329-336.

22. Gayther, S.A.; Mangion, J.; Russell, P.; Seal, S.; Barfoot, R.; Ponder, B.A.; Stratton, M.R.; Easton, D. Variation of risks of breast and ovarian cancer associated with different germline mutations of the BRCA2 gene. Nat. Genet. 1997, 15, 103-105. [CrossRef] [PubMed]

23. Thompson, D.; Easton, D. Variation in Cancer Risks, by Mutation Position, in BRCA2 Mutation Carriers. Am. J. Hum. Genet. 2001, 68, 410-419. [CrossRef] [PubMed] 
24. Lubinski, J.; Phelan, C.M.; Ghadirian, P.; Lynch, H.T.; Garber, J.; Weber, B.; Tung, N.; Horsman, D.; Isaacs, C.; Monteiro, A.N.A.; et al. Cancer variation associated with the position of the mutation in the BRCA2 gene. Fam. Cancer 2004, 3, 1-10. [CrossRef]

25. Labidi-Galy, S.I.; Olivier, T.; Rodrigues, M.; Ferraioli, D.; Derbel, O.; Bodmer, A.; Petignat, P.; Rak, B.; Chopin, N.; Tredan, O.; et al. Location of Mutation in BRCA2 Gene and Survival in Patients with Ovarian Cancer. Clin. Cancer Res. 2018, $24,326-333$. [CrossRef]

26. Alsop, K.; Fereday, S.; Meldrum, C.; DeFazio, A.; Emmanuel, C.; George, J.; Dobrovic, A.; Birrer, M.J.; Webb, P.M.; Stewart, C.; et al. BRCA Mutation Frequency and Patterns of Treatment Response in BRCA Mutation-Positive Women with Ovarian Cancer: A Report From the Australian Ovarian Cancer Study Group. J. Clin. Oncol. 2012, 30, 2654-2663. [CrossRef]

27. Bayraktar, S.; Jackson, M.; Gutierrez-Barrera, A.M.; Liu, D.; Meric-Bernstam, F.; Brandt, A.; Woodson, A.; Litton, J.; Lu, K.H.; Valero, V.; et al. Genotype-Phenotype Correlations by Ethnicity and Mutation Location in BRCA Mutation Carriers. Breast J. 2015, 21, 260-267. [CrossRef]

28. Ghezelayagh, T.S.; Pennington, K.P.; Norquist, B.M.; Khasnavis, N.; Radke, M.R.; Kilgore, M.R.; Garcia, R.L.; Lee, M.; Katz, R.; Leslie, K.K.; et al. Characterizing TP53 mutations in ovarian carcinomas with and without concurrent BRCA1 or BRCA2 mutations. Gynecol. Oncol. 2021, 160, 786-792. [CrossRef]

29. DiSilvestro, P.; Colombo, N.; Scambia, G.; Kim, B.-G.; Oaknin, A.; Friedlander, M.; Lisyanskaya, A.; Floquet, A.; Leary, A.; Sonke, G.S.; et al. Efficacy of Maintenance Olaparib for Patients with Newly Diagnosed Advanced Ovarian Cancer with a BRCA Mutation: Subgroup Analysis Findings From the SOLO1 Trial. J. Clin. Oncol. 2020, 38, 3528-3537. [CrossRef]

30. Konstantinopoulos, P.A.; Ceccaldi, R.; Shapiro, G.I.; D'Andrea, A.D. Homologous Recombination Deficiency: Exploiting the Fundamental Vulnerability of Ovarian Cancer. Cancer Discov. 2015, 5, 1137-1154. [CrossRef]

31. The Cancer Genome Atlas Research Network. Undefined Integrated Genomic Analyses of Ovarian Carcinoma. 2011. Available online: https:/ / www.ncbi.nlm.nih.gov/pmc/articles/PMC3163504/ (accessed on 12 September 2021).

32. Coleman, R.L.; Monk, B.J.; Sood, A.K.; Herzog, T.J. Latest research and treatment of advanced-stage epithelial ovarian cancer. Nat. Rev. Clin. Oncol. 2013, 10, 211-224. [CrossRef] [PubMed]

33. Bookman, M.A.; Tyczynski, J.E.; Espirito, J.L.; Wilson, T.W.; Fernandes, A.W. Impact of primary platinum-free interval and BRCA1/2 mutation status on treatment and survival in patients with recurrent ovarian cancer. Gynecol. Oncol. 2017, 146, 58-63. [CrossRef]

34. Gallotta, V.; Conte, C.; D’Indinosante, M.; Capoluongo, E.; Minucci, A.; De Rose, A.M.; Ardito, F.; Giuliante, F.; Di Giorgio, A.; Zannoni, G.F.; et al. Prognostic factors value of germline and somatic brca in patients undergoing surgery for recurrent ovarian cancer with liver metastases. Eur. J. Surg. Oncol. (EJSO) 2019, 45, 2096-2102. [CrossRef] [PubMed]

35. Gallotta, V.; Bruno, M.; Conte, C.; Giudice, M.; Davià, F.; Moro, F.; Zannoni, G.; Fagotti, A.; De Bonis, M.; Capoluongo, E.; et al. Salvage lymphadenectomy in recurrent ovarian cancer patients: Analysis of clinical outcome and BRCA1/2 gene mutational status. Eur. J. Surg. Oncol. (EJSO) 2020, 46, 1327-1333. [CrossRef]

36. Javle, M.; Curtin, N.J. The role of PARP in DNA repair and its therapeutic exploitation. Br. J. Cancer 2011, 105, 1114-1122. [CrossRef]

37. Drost, R.; Bouwman, P.; Rottenberg, S.; Boon, U.; Schut, E.; Klarenbeek, S.; Klijn, C.; van der Heijden, I.; van der Gulden, H.; Wientjens, E.; et al. BRCA1 RING Function Is Essential for Tumor Suppression but Dispensable for Therapy Resistance. Cancer Cell 2011, 20, 797-809. [CrossRef]

38. Jonsson, P.; Bandlamudi, C.; Cheng, M.L.; Srinivasan, P.; Chavan, S.S.; Friedman, N.D.; Rosen, E.Y.; Richards, A.L.; Bouvier, N.; Selcuklu, S.D.; et al. Tumour lineage shapes BRCA-mediated phenotypes. Nature 2019, 571, 576-579. [CrossRef]

39. Eoh, K.J.; Kim, H.M.; Lee, J.-Y.; Kim, S.; Kim, S.W.; Kim, Y.T.; Nam, E.J. Mutation landscape of germline and somatic BRCA1/2 in patients with high-grade serous ovarian cancer. BMC Cancer 2020, 20, 1-8. [CrossRef]

40. Apostolou, P.; Fostira, F.; Kouroussis, C.; Kalfakakou, D.; Delimitsou, A.; Agelaki, S.; Androulakis, N.; Christodoulou, C.; Kalbakis, K.; Kalykaki, A.; et al. BRCA1 and BRCA2 germline testing in Cretan isolates reveals novel and strong founder effects. Int. J. Cancer 2020, 147, 1334-1342. [CrossRef] [PubMed] 